\title{
Cultivating a career: Effects of television binge-watching and character identification on college students' goal occupations
}

Jordan Morgan

Faculty Mentor: Dr. Jessica Myrick, The Media School Indiana University

ABSTRACT

This paper focuses on the effects that heavy television viewing can have on viewers' life choices. Specifically, it investigates how television can influence their desires to be like favorite characters and to obtain a goal occupation that aligns with that of their favorite characters. This study surveyed undergraduate students at Indiana University to see if their favorite characters on popular career-based television shows could have influenced their major and career choice. Respondents were also surveyed to see if the act of binge watching heightened the likelihood of a viewer's goal occupation that corresponding with the career of their favorite character. The results showed that there was some correspondence between favorite characters' careers and viewers' goal occupations. However, the results showed no significant difference in the effects of binge watching.

KEYWORDS: cultivation theory, identification theory, communication, character identification

\section{INTRODUCTION}

$\mathrm{M}$ ost social scientific theories of mass communication share the idea that media has the ability to affect and shape aspects of the human experience, such as values and even decision-making. One particularly influential channel of mass media is television. Many studies have been conducted regarding the relationship between television consumption effects on viewers. Identification studies have shown that heavy television viewers tend to develop psychological attachments, or identification, with media characters. For example, Hoffner and Buchanan (2005) found that young adults tend to develop wishful identification with favorite television characters of the same gender as themselves and whom they perceived as sharing their own attitudes.

However, there is currently a gap in the literature regarding the ways in which frequent television viewing and identification with characters may influence young adults' perceptions of careers or college majors. Explicitly, we wondered if heavy-television viewing of career-focused shows results in viewers choosing majors that correspond with the career of their favorite characters. Additionally, the ability for viewers to binge-watch many episodes could amplify the correspondence between viewers' chosen career path and that of their favorite character.

To address these issues, we surveyed 734 students at Indiana University regarding their television viewing habits, their choice of major, goal occupation, and favorite television shows and characters. The aim of this study was to determine the possible affects that career-based television shows may have on viewers' decision for college major or goal occupation. The knowledge from this study allows us to better understand television's effects on human behavior.

\section{LITERATURE REVIEW}

Identification theory holds that viewers can undergo an imaginative process in which the individual forgets his or her own identity to take on the identity of someone else (Wolheim, 1973). Specifically looking at entertainment media, if one individual strongly identifies with a character in a show, a strong sense of aspiration to be that character could develop. This could cause them to follow the character's path in life, including choice of profession. For example, previous researchers found that a relationship does exist between occupational aspirations and amount of television watched (Hoffner et al., 2006). Prior literature also suggests that frequency of viewing and the extrinsic rewards of the favorite character's job, as well as income and education level of the favorite character, are all positive predictors of wishful identification (Hoffner, 2005).

Few studies have been conducted on media's portrayal of careers and the influence it can have on audiences. However, media's portrayal of groups in the workplace has been looked at. Although they did not empirically test their proposition, Harris and Sanborn (2014) identify the unrealistic solidarity amongst co-workers and professionals by the media and suggest it might influence audience members' career aspirations. The authors point out that shows like The Office and Grey's Anatomy depict the workplace as becoming a surrogate family (Harrison \& Sanborn 2014). This workplace solidarity is also extended to the clients of the professionals. The doctors on Grey's Anatomy often spend their free time or days off seeking out or helping patients in need (Harrison \& Sanborn 2014). Thus, an unrealistic portrayal of a profession might also influence career choices, particularly if a viewer relates strongly to one of the characters on that show.

According to Bandura's Social Cognitive Theory or Social Learning Theory, human behavior can be acquired through observation and modeling (Bandura 2001). This theory explains how individual's behavior can be shaped and developed by the observation of others. Many behaviors can be observed and modeled from the media, and mediated modeling of behaviors related to careers could possibly even influence one's decision to pursue a certain career.

While cultivation theory, social cognitive theory, and 
research on audience identification with characters all suggest that there might be a relationship between television viewing and audience career goals, another factor may be at play in the modern media environment. Today, individuals can watch hours of their favorite shows all in a row instead of waiting to watch only one hour or half our per week. According to Matrix (2014), binge-watching platforms, such as Netflix, are changing how viewers watch TV and increasing the amount of TV they consume. Teen viewers reported in a Stage of Life study that they learned to set new goals and follow their dreams through watching their favorite shows (Matrix, 2014).

Based on the aforementioned literature, we pose the following two research questions:

RQ1: What is the relationship between the viewers' goal career and their favorite character's occupation?

RQ2: What is the relationship between bingewatching and occupation-based show and viewers' goal career?

\section{METHODOLOGY}

\subsection{Participants}

Participants were recruited via a random sampling of students at Indiana University. The final sample of respondents $(N=734), 34.6 \%$ identified as male, $61.0 \%$ identified as female, and $0.4 \%$ identified as transgender. Additionally, $79.4 \%$ of the final sample identified as White/ Caucasian, 11.9\% identified as Asian, 4.1\% identified as Black/African-American, 1.0\% identified as American Indian or Native Alaskan, and another 3.5\% identified as "other" (respondents could select more than one race with which they identified. As for ethnicity, $7.4 \%$ of the final sample identified as Hispanic. The average age of the respondents in our sample was 22.88 years $(S D=5.35$ years).

\subsection{Procedures}

In order to randomly sample the student body (including undergraduate and graduate students) at a large public institution in the Midwestern United States, the researchers visited the registrar's office and viewed the publicly available (hard copy) list of student emails. There were 902 total pages of emails, and each page contained the email addresses of approximately 48 students. A picture of every ninth page (101 total pages) was taken with the goal of collecting approximately 5,000 email addresses. Due to the different number of names on each page, the final number of email addresses collected was 4,571. Those addresses were uploaded into Qualtrics software. Qualtrics was programmed to send a link to the online questionnaire along with information about the incentive to participate (entry in a random drawing for one of four \$50 USD gift cards to Amazon.com) to the 4,571 email addresses.
The questionnaire began with demographics, current major, and goal occupation inquiries. Then, the questionnaire asked general questions about binge watching before respondents reported their viewing habits of 20 popular television series. Each of these series is available to view online in some form, assuring that respondents could potentially binge watch them. At the end of the questionnaire, respondents were given the option to click on a link to separate website to enter their names and email addresses for the gift card drawing. This procedure allowed participants to enter the drawing without having their identity associated with their survey responses. The online questionnaire was open for two weeks and all procedures were approved by the university's institutional review board. Of those 4,571 individuals who were sent a message about the survey opportunity, four had email addresses that bounced back as undeliverable, but 2,234 people (48.9\% of the deliverable addresses) did open the email. Of those, 750 students started the online questionnaire and 734 finished it, making for an overall completion rate of $16.1 \%$, or $32.9 \%$ of those who actually opened the email.

\subsection{Measures}

After asking about demographics (i.e., gender, age, race, ethnicity), participants were asked about their goal occupation with the following prompt: "What is your goal occupation? That is, what do you ideally want your profession (your job) to be after you graduate?" Next, their responses were recoded by two coders into one of 33 general categories. Respondents were then asked if they had ever seen any of 20 popular television series. Table 1 details the results of this inquiry, with Friends, How I Met Your Mother, and The Office (US version) the most commonly seen in our sample.

For each show that respondents reported having seen at least once, they were then asked how they viewed the shows, with 13 different response options, ranging from watching it "when it airs (or when it originally aired) on TV," or "Single episodes online via the network/channel website or mobile app" to "Multiple episodes at a time on OnDemand." Five of those options were specifically designed to assess if participants binge-watched the show: "Multiple episodes at a time during marathons on TV;" "Multiple episodes at a time online via the network/ channel website or a mobile app;" Multiple episodes at a time on Netflix, Amazon, Hulu, or iTunes; "Multiple episodes at a time on OnDemand (e.g., from your cable or satellite provider);" and "Multiple episodes at a time online for free using BitTorrent or similar websites." If a respondent chose any one of those five responses (or even multiple ones of them), we coded that as having bingewatched the show. Table 2 lists the percentage of viewers who binge-watched each show, with Parks and Recreation, Friends, and How I Met Your Mother being the two most popular binge-watching options of the 20 shows in our sample. 
Table 1. Frequency of having seen the show at least once

\begin{tabular}{lr}
\hline Show & Frequency \\
Friends & 454 \\
How I Met Your Mother & 403 \\
The Office (US version) & 394 \\
Parks and Recreation & 356 \\
House M.D. & 296 \\
New Girl & 275 \\
Grey's Anatomy & 273 \\
Gilmore Girls & 249 \\
Sex and the City & 228 \\
Criminal Minds & 224 \\
House of Cards & 216 \\
CSI & 179 \\
Scandal & 149 \\
Castle & 118 \\
The Mindy Project & 111 \\
The X-Files & 109 \\
ER & 105 \\
The Blacklist & 86 \\
Entourage & 80 \\
Homeland & 60 \\
\hline
\end{tabular}

\section{RESULTS}

Final analyses were based on the five most popular shows in the sample (i.e., the five shows with the most respondents reporting as having seen at least once). These shows (Friends, How I Met Your Mother, The Office, Parks and Recreation, and House M.D.) included portrayals of a number of occupations, from actor or professor to government worker or healthcare provider. As such, they provided a nice crosssection of popular shows and popular occupations for which to address the research questions connecting styles of television viewing (binging versus tradition, single-show viewing) and the occupational goals of young adult viewers.

The first research question asked about the relationship between the viewers' goal occupation and their favorite character's occupation. Table 3 reports the percentages of viewers who had a match in between their stated goal occupation and their stated favorite character's occupation.

The second research question asked about the relationship between binge-watching a show and the match between the viewer's goal occupation and favorite character's occupation. To address this research question, statistical analyses were run comparing the number of respondents who reported any type of binge-watching of each of the five most popular shows in our sample against the numbers for each show who had a match in their goal career and their favorite character's career. First, a Pearson Chi-Square analysis was run with the 308 respondents who reported a favorite character on Friends other than the "other" option and using the continuity correction required for 2-by-2 tables. The analysis revealed there was a not a significant difference in the likelihood of having a career match with one's favorite character based on whether or not individuals binge-watched Friends, $\chi 2(\mathrm{df}=1)$ $=.22, p=.64$. Another Pearson Chi-Square analysis was run with the 310 respondents who reported a favorite character on How I Met Your Mother other than the "other option" and using the continuity correction required for 2-by-2 tables. The analysis revealed there was a not a significant difference in the likelihood of having a career match with one's favorite character based on whether or not individuals binge-watched How I Met Your Mother, $\mathrm{X} 2(\mathrm{df}=1)=.21, p=.65$.

Another Pearson Chi-Square analysis was run with the 269 respondents who reported a favorite character on The Office other than the "other" option and using the continuity correction required for 2-by-2 tables. The analysis revealed there was a not a significant difference in the likelihood of having a career match with one's favorite character based on whether or not individuals binge-watched The Office, $\chi 2(\mathrm{df}=1)=.03, p=.86$. Another Pearson Chi-Square analysis was run with the 244 respondents who reported a favorite character on Parks \& Recreation other than the "other" option and using the continuity correction required for 2-by-2 tables. The analysis revealed there was a not a significant difference in the likelihood of having a career match with one's favorite character based on whether or not individuals binge-watched Parks \& Recreation, $\chi 2(\mathrm{df}=$ 1) $=.00, p=1.00$.

A final Pearson Chi-Square analysis was run using only the data for those who reported having a favorite character on House M.D. other than the "other" option $(n=199)$. This analysis also used the continuity correction required for 2-by-2 tables. It revealed there was a not a significant difference in the likelihood of having a career match with one's favorite character based on whether or not individuals binge-watched House M.D., $\chi 2(\mathrm{df}=1)=1.01, p=.32$. In summary, there were no statistically significant differences in the likelihood of having a match between one's goal career and one's favorite character's career based on having bingewatched the show. 


\section{DISCUSSION}

Our first research question asked if there is a relationship between the media viewers' goal career and their favorite character's occupation. Analyses determined that there is some association between the two; however, the correspondence is small. Nonetheless, these findings suggest that identification may be at play and influencing media viewers' career choice based on character occupation. House M.D. had the greatest percentage of character career/goal occupation alignment with a $13.9 \%$ of respondents having a match with their goal occupation and their favorite character's career. Friends was reported as the most watched show among respondents, and out of those 454 viewers, $3.52 \%$ had a match between their goal occupation and their favorite character's occupation. Most notably, $34.8 \%$ of the respondents who listed Ross as their favorite character also reported working as a professor as their goal occupation.

Identification serves as one possible justification for these character career/goal occupation matches. For instance, the reason House M.D. had the highest percentage of character career/goal occupation overlap could be due to the fact that all of the characters are flawed, and therefore more relatable, which could heighten identification in viewers. Foundational studies on identification have determined that perceived similarity is an important component of identification. The realistic portrayals of the House M.D. characters could strengthen identification bonds (Hoffner \& Buchanan, 2005). Genre of the television show could also impact identification between viewer and character, as previous literature indicates stronger parasocial relationships between characters in dramas, such as soap operas, and female viewers (Kanazawa, 2002; Turner, 1993). Future studies could analyze other potential factors that may heighten the character/career matches.

Our second research question addressed whether binge watching strengthened the relationship between favorite character career and goal occupation. Results indicate that there was no significant relationship between a character career/goal occupation match and binge watching of the show. One possible explanation is that as bingewatching intensifies, other aspects of the character/viewer relationship, such as wishful identification with the favorite character's personality traits, may become more salient than the potential influence on career choice, especially in college-aged viewers. Future work in this area could study younger audiences who are likely less confident about professional aspirations, and therefore may be more impacted by binge-watching, in comparison to the collegeaged students in the present work.

While this study provides important exploratory analyses of media effects at play between career aspirations, identification with mediated characters, and binge watching, no work is without limitations. For instance, the present study did not account for how each show portrayed the occupations of their characters, and if that affected whether
Table 3. Correspondence between favorite characters and goal occupations for the five most popular shows in the sample

$\begin{array}{lll}\text { Show } & \begin{array}{l}\text { Seen } \\ \text { Show }\end{array} & \begin{array}{l}\text { Favorite } \\ \text { Character }\end{array} \\ \text { Friends } & 454 & \begin{array}{l}\text { Ross }-23 \\ \text { Monica }-31 \\ \text { Chandler }-91 \\ \text { Joey }-43 \\ \\ \end{array} \\ & \begin{array}{l}\text { Rachel }-66 \\ \text { Phoebe }-54 \\ \text { Other }-15\end{array} \\ & \end{array}$

Goal occupation matches favorite character's occupation

$8(34.8 \%)$

$0(0 \%)$

$7(7.7 \%)$

$0(0 \%)$

$1(1.5 \%)$

$0(0 \%)$

$\mathrm{N} / \mathrm{A}$

How I Met

Your Mother

403

Barney - 133

Ted - 39

Marshall - 70

Lily - 36

Robin - 32

Other - 14

The Office

(US version)

394

Dwight - 48

Michael - 77

Jim - 98

Pam - 19

Angela - 5

Andy - 3

Phyllis - 1

Creed -8

Oscar - 1

Darryl - 2

Kelly Erin - 1

Kelly Kapoor - 6

Other - 9

Parks and

Recreation

$$
356
$$

Leslie - 89

Ron -80

Tom -19

April - 26

Andy - 14

Ann - 3

Ben - 3

Chris -5

Jerry - 2

Donna -3

Other -7

House M.D.

$296 \quad \begin{aligned} & \text { House }-148 \\ & \text { Foreman }-7 \\ & \text { Wilson }-15 \\ & \text { Chase }-8 \\ & \text { Cuddy }-9 \\ & \text { Cameron }-4 \\ & \text { Taub }-1 \\ & \text { Thirteen }-7 \\ & \text { Other }-4\end{aligned}$

$32(21.6 \%)$

$1(14.3 \%)$

$4(26.7 \%)$

$0(0 \%)$

$1(11.1 \%)$

$1(25.0 \%)$

$0(0 \%)$

2 (28.6\%) $\mathrm{N} / \mathrm{A}$

there was a character career/ goal occupation match. For example, The Office is considered a largely popular show; respondents rated it as the third most-watched show with a total of 394 viewers. However, only $2.53 \%$ of those 
respondents had a match with their goal occupation and favorite character. There may be a significant relationship between the way the sales careers are portrayed in The Office and desirability of the career with regard to viewers' goal occupation. Michael Scott may be a lovable and favorite character to many, but only $7.8 \%$ of respondents who listed him as their favorite character had a goal occupation match with his occupation. It's possible that being the regional sales manager of a paper company in the Midwest might not be portrayed as an appealing career, especially when the crux of cultivation theory - that media can cause people to believe that mediated portrayals correspond to actual reality - is considered (Gerbner, 1998).

While further research is needed to systematically parse out the relationship between binge watching and the aforementioned identification and cultivation effects, this study presents an important, exploratory examination of how present-day media viewing trends may be impacting the viewer relationships with mediated characters.

\section{AUTHOR INFORMATION}

All correspondence should be sent to the first author: jordmorg@indiana.edu.

\section{REFERENCES}

Hoffner, C., \& Buchanan, M. (2005). Young adults' wishful identification with television characters: The role of perceived similarity and character attributes. Media Psychology, 7, 325-351.

Hoffner, C., Levine, K. J., Sullivan, Q. E., Crowell, D., \& Pedrick, L. (2006). Television's Role in the Occupational Aspirations of Economically Disadvantaged Youths. Journal of Career Development, 33(1), 3-18.

Kanazawa, S. (2002). Bowling with our imaginary friends. Evolution and Human Behavior, 23, 167-171.

Turner, J. R. (1993). Interpersonal and psychological predictors of parasocial interaction with different television performers. Communication Quarterly, 41, 443-453.

Bandura, A. (2001). Social cognitive theory of mass communication. Media Psychology, 3(3), 265-299. doi:10.1207/s1532785xmep0303_03

Harris, R.J., \& Sanborn, F.W. (2014). A Cognitive Psychology of Mass Communication. 116.

Tsetsura, K., Bentley, J., \& Newcomb, T. (2014). Idealistic and Conflicted: New Portrayals of Public Relations Practitioners in Film. Public Relations Review 41.5. 652-61.

Wollheim, R. (1974). Imagination and Identification. On Art and Mind. 52-77. 
